ISSN 1991- 8690

website :http:// jsci.utq.edu.iq

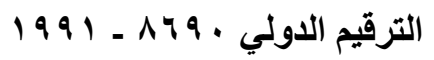

Email: utjsci@utq.edu.iq

\title{
Characterization of Lactobacillus as probiotic from human intestine
}

\author{
Saad S. F.
}

Adnan H. Abbas

Ministry of Science and Technology

\author{
Sahar G. I.
}

\begin{abstract}
$\underline{\text { Absract }}$
In order to perform a selective isolation of bacteria tightly bound to the human gut, ileal biopsies of healthy volunteers were treated to wash out the mucus layer and loosely bound bacterial cells. Rod-shaped, anaerobic bacteria that had remained attached to the epithelial cells were isolated and identified at the species level by biochemical tests. One isolate was identified as Bifidobacterium breve, while all the others were Lactobacilli of only two species, Lactobacilus mucosae and L. gasseri. Members of these species were found previously along with many others in intestinal samples but their predominance among bacteria strictly associated to the epithelium, as shown here, was not suspected before and suggested that these species may represent a specific sub-population of tissue-bound bacteria. A series of physiological tests was performed and indicated that all isolates were able to produce antimicrobial activity against selected pathogens and survive simulated gastric conditions. All isolates were able to grow and produce biofilm in intestinal fluid after exposure to gastric conditions. Those isolates can be proposed as potential probiotic strains for human use.
\end{abstract}

Keywords: Lactobacillus, gut, commensals, probiotics, mucus

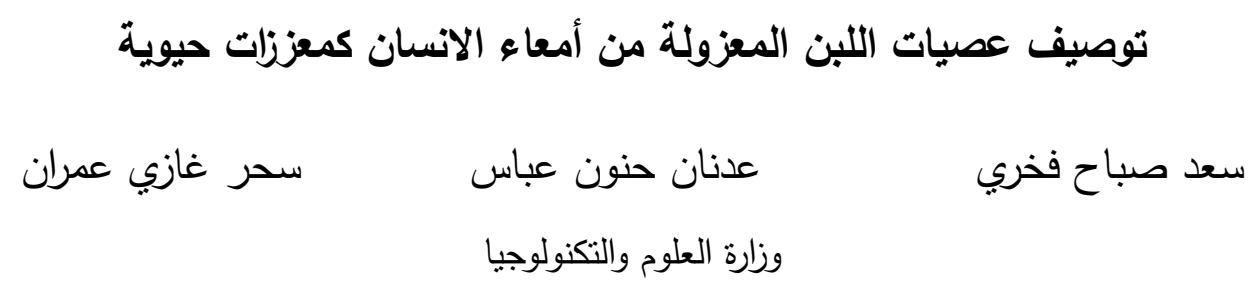

الخلاصـة

جمعت عزلات بكتبرية مختارة عن طريق غسل الطبقة المخاطية وأخذ قطعة حية من معدة ولفائفي المنبرعين الاصحاء. تم عزل البكتريا الملتصقة

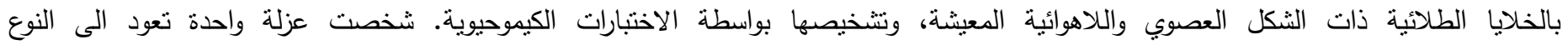

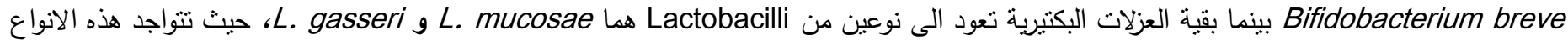

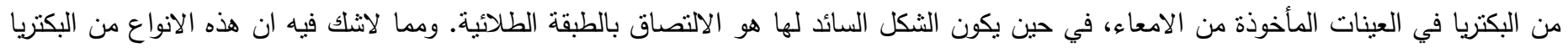

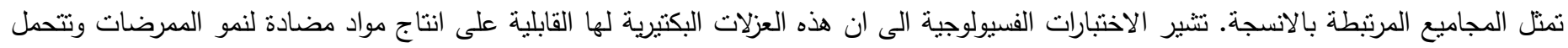

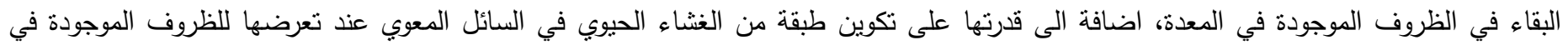
المعدة وكذللك تعمل كمعززات حيوية فعالة في الانسان.

\section{Introduction}

The human intestinal microflora establishes a complex symbiotic interaction with epithelial and immune cells of the gastrointestinal tract (GIT). In this interaction the microbial role is essential in providing nourishment, forming a first line of defense against 
invasion by pathogenic organisms, regulating epithelial development and inducing innate immunity (7). These contributions are reciprocated by stable conditions of temperature, $\mathrm{pH}$, osmolarity and food supply for the microorganisms. Recent metagenomic experiments have indicated that the vast majority of the intestinal bacteria belong to two phyla, Firmicutes, including the large class of Clostridia and the lactic acid bacteria (LAB) and Bacteroidetes (7, 15). Most of these organisms are anaerobes and not cultivable in laboratory conditions and only $0.1 \%$ of the total gut bacteria are facultative anaerobes (7). However, the composition of the gut microbiota is known to vary transiently as a consequence of diet changes, enteral infections, antibiotic or anti-acid treatments and immune suppression (18). Recently, it has been shown that phylum-level changes in the microflora are associated with diseases, such as obesity (19). In particular, the coexistence of $\mathrm{H} 2$-producing bacteria and H2-utilizing methanogenic Archaea in the GIT of obese individuals induced to hypothesize that $\mathrm{H} 2$ transfer between Eubacteria and Archaeal species increases the energy uptake by the large intestine of obese individuals (23). At the species level a large diversity exists in the human gut. It is known that the type of neonatal feeding influences the species composition of the microflora (4) and that in the elderly a general reduction in species diversity occurs, with an increase of facultative anaerobes and a decrease of Lactobacilli and Bifidobacteria (11, 21). Lactobacilli and Bifidobacteria, were the most frequently used as probiotic products for human consumption. Lactobacilli, with all other $\mathrm{LAB}$, are low $\mathrm{G}+\mathrm{C}$, grampositive and belong to the phylum of the Firmicutes, while Bifidobacteria are high $\mathrm{G}+\mathrm{C}$, gram-positives and belong to the phylum of the Actinobacteria (20). Bifidobacteria, like all Actinobacteria, are not numerically important in the intestine, their number is higher in breast-fed than in formula-fed infants and decreases in adults $(4,18)$. In spite of their number, Bifidobacteria are thought to play a relevant role in keeping the gut health (13) and cells of Bifidobacterium longum have been shown in reduction of intestinal inflammation by efficiently inhibiting pancreatic and neutrophilic elastases (9). Not much attention has been given so far to whether bacteria isolated from the animal gut bind tightly or loosely to the epithelium and whether physical interactions between bacterial cells and animal tissue is relevant for probiotic activity of intestinal microflora. To gain insight into this problem we followed a previously reported procedure (17) to separate the mucus layer from the epithelial tissue of ileal biopsies of healthy human volunteers and found that only a small minority of ileal bacteria remains attached to the human cells after this treatment. Among these tightly bound bacteria we focused our attention on eleven anaerobic rod-shaped strains that would more likely display a probiotic function in the gut and report here on some of their relevant properties.

\section{Materials and methods}

\section{Collection of ileal samples}

Mucosal samples were collected by forceps biopsy in the distal ileum from 7 adult human volunteers $(\mathrm{M} / \mathrm{F}$ $4 / 3$, mean age $\pm \mathrm{SD} 45.0 \pm 13$ ) undergoing routine diagnostic endosocopy for colorectal cancer (CRC) screening. All patients recruited gave their informed consent to the study. The patients did not follow any special dietary regimen, and had not recently received any antibiotic or probiotic treatment. Samples were stored in phosphate-buffered saline (PBS) containing $15 \%$ glycerol before subsequent analysis. Endoscopic appearance as well as histology of the ileum was normal in all patients.

\section{Bacterial isolation and culture conditions}

Ileal samples (10-20 mg/each) were treated with DTT as previously reported (18), extensively washed with PBS to eliminate loosely attached bacteria. Tissue samples after the washes, as well as buffer recovered from each wash, were plated on deMan, Rogosa and Sharpe medium (MRS) (Difco) in anaerobic condition to isolate lactic acid bacteria. Anaerobic conditions were obtained by incubating liquid and solid cultures in an anaerobic chamber (Oxoid).

\section{Physiological and biochemical analysis}

Exponentially growing cells of the various isolates were used for biochemical analysis by the use of API $50 \mathrm{CHL}$ Kit (Biomerieux) following the manufacturer's instructions. For biofilm formation bacteria were grown in modified TSB (mTSB) medium as described by Lebeer et al., (2007): $15 \mathrm{~g} /$ liter TSB (BD Biosciences) enriched with $20 \mathrm{~g} /$ liter Bacto peptone No. 3 (BD Biosciences). Antimicrobial activity was determined as previously described (2) with the following modifications: $10 \mu \mathrm{l}$ of each culture in stationary growth phase were spotted on the surface of an MRS agar plate and the spots air dried. A $100 \mu$ of an exponential culture of the indicator bacterial strain obtained from laboratories of hospitals, were mixed with $5 \mathrm{ml}$ of soft agar $(0.7 \%)$ and poured over the plate. The plates were incubated aerobically overnight at 
$37^{\circ} \mathrm{C}$ and the inhibition halos were measured and expressed in $\mathrm{mm}$.

\section{Simulated gastric and intestinal fluids}

Gastric and intestinal fluids (SGF and SIF) were simulated as previously reported (8). Exponentially growing cells were washed, resuspended in SGF (PBS $0.5 \% \mathrm{w} / \mathrm{v}$, pepsin $3 \mathrm{~g} / \mathrm{l}, \mathrm{pH} 2.0$ ) or SIF (PBS $0.5 \% \mathrm{w} / \mathrm{v}$, pancreatin $1 \mathrm{~g} / \mathrm{l}, \mathrm{pH} \mathrm{8.0)}$ ) and incubated 1 hour at $37^{\circ} \mathrm{C}$. Cells were then diluted, plated on MRS plates and incubated at $37^{\circ} \mathrm{C}$ in anaerobic conditions. To monitor growth in simulated intestinal condition after gastric treatment, exponentially growing cells were washed, resuspended in SGF (PBS 0.5\% w/v, pepsin $3 \mathrm{~g} / \mathrm{l}, \mathrm{pH}$ 2.0) and incubated 1 hour at $37^{\circ} \mathrm{C}$. Then cells were diluted at 0.05 OD600nm in MRS supplemented with pancreatin $(1 \mathrm{~g} / \mathrm{l}, \mathrm{pH} 8.0)$, incubated at $37^{\circ} \mathrm{C}$ in anaerobic conditions and growth monitored after 18 hours.

\section{In vitro biofilm assay}

Biofilm formation was assayed as in reference (15). Briefly, a platform carrying 96 polystyrene wells was filled with $200 \mu \mathrm{l}$ medium. Approx. 3x107 CFU were added and incubated without shaking for $24 \mathrm{~h}$ at $37^{\circ} \mathrm{C}$. To quantify biofilm formation, the wells were briefly washed in phosphate-buffered saline (PBS). The remaining attached bacteria were stained for $30 \mathrm{~min}$ with $200 \mu 10.1 \%$ (w/v) crystal violet in an isopropanolmethanol-PBS solution $(1: 1: 18 \mathrm{v} / \mathrm{v})$. Excess stain was washed with water. Wells were air dried $(30 \mathrm{~min})$, the dye bound to the wells was extracted with $200 \mu \mathrm{l}$ ethanol-acetone $(80: 20 \mathrm{v} / \mathrm{v})$ and the optical density (OD) was measured at $570 \mathrm{~nm}$. Each strain was tested in at least three independent experiments, each with three biological replicates. Data were normalized to the indicated positive control (LGG), which was taken as $100 \%$ to compare different experiments. Additionally, sterile medium was always included (negative control)

\section{$\underline{\text { Results }}$}

\section{Isolation of Lactobacilli from ileal epithelial cells}

In order to restrict our isolation to bacteria tightly associated to the human tissue, samples of ileal biopsies of healthy human volunteers, collected as described in Materials and Methods, were treated with DTT and extensively washed with PBS to eliminate the mucus layer, as previously reported (18). Biopsy samples, as well as buffers recovered from each wash, were used to isolate lactic acid bacteria (LAB) by plating on MRS medium in anaerobic condition. The majority of the bacteria present in the ileal samples were found in the buffer recovered after the washes with an average of $3.54 \times 103 / \mathrm{mg}$ and $2.21 \times 103 / \mathrm{mg}$ of aerobic bacteria and $\mathrm{LAB}$, respectively. A lower number of bacteria with an average of $16 / \mathrm{mg}$ and $10 / \mathrm{mg}$ of aerobic bacteria and $\mathrm{LAB}$, respectively, were found tightly attached to ileal epithelial cells. Bacteria able to grow anaerobically on MRS medium were analyzed for their colony morphology on MRS plate, Gram-staining and catalase phenotype. Only one colony of those apparently identical from each ileal sample was selected, analysed for their cell shape under the light microscope and divided into two groups: round and rod-shaped bacteria. By this procedure we ended up with 24 isolates: 13 round-shaped and 11 rod-shaped. With the aim of characterising potential probiotic Lactobacilli, we focused our attention on the rod-shaped bacteria that were characterised at the species level by biochemical tests (API gallery). As a result of the eleven rod-shaped isolates, one isolate was identified as Bifidobacterium breve, while the remaining ten were belonged to Lactobacilli, containing L. mucosae (eight isolates) and L. gasseri (two isolates) (Table 1), only strains SF1087, SH1091 and SH1108, belonging to the same species and coming from the same ileal biopsy, could be potential siblings.

Table 1. Rod-shaped bacteria tightly associated to ileal epithelial cells

\begin{tabular}{|c|c|l|}
\hline Biopsy No. & Strain name & \multicolumn{1}{|c|}{ Species } \\
\hline 1 & SH1031 & Lactobacillus mucosae \\
\hline 1 & SH1036 & Bifidobacterium breve \\
\hline 2 & SH1087 & Lactobacillus mucosae \\
\hline 2 & SH1091 & Lactobacillus mucosae \\
\hline 2 & SH1108 & Lactobacillus mucosae \\
\hline 2 & SH1109 & Lactobacillus gasseri \\
\hline 3 & SH1111 & Lactobacillus mucosae \\
\hline 4 & SH1146 & Lactobacillus mucosae \\
\hline 5 & SH1183 & Lactobacillus gasseri \\
\hline 6 & SH1232 & Lactobacillus mucosae \\
\hline 7 & SH1233 & Lactobacillus mucosae \\
\hline
\end{tabular}

${ }^{\mathrm{a}}$ Assessed on the base of biochemical tests. 


\section{Production of antimicrobial activity}

All Lactobacilli were analysed for the production of antimicrobial molecules active against selected pathogens (Table 2). An exponential culture of each of the 11 isolates was used to 'spot' sterile LB plates. As previously reported (2), the spots were air-dried and used to overlay soft agar $(0.7 \%)$ containing exponential cells of one of the indicator strains obtained. Solidified plates were then incubated at the appropriate temperature for 18-24 hours and the appearance of a growth-inhibition halo taken as an indication of the presence of an antimicrobial activity. As summarized in Table (2), all strains produced antimicrobial molecules, active against the Gram-positive and the Gram-negative pathogens used in our study. As a control we used strains LGG, It is interesting to note that, while all our ileal isolates produced similar antimicrobial activities, the three Lactobacillus strains from other sources showed a more heterogeneous profile of production of antimicrobial molecules.

Table 2. Antimicrobial activity against selected pathogens

\begin{tabular}{|c|c|c|c|c|c|c|}
\hline Strain & $\begin{array}{l}\text { Bacillus } \\
\text { cerens }\end{array}$ & $\begin{array}{c}\text { Stuplyllococcus } \\
\text { aures }\end{array}$ & $\begin{array}{c}\text { Listeris } \\
\text { monocytogenes }\end{array}$ & $\begin{array}{l}\text { Salmonella } \\
\text { tphimuritinn }\end{array}$ & $\begin{array}{l}\text { Shigello } \\
\text { soni }\end{array}$ & $\begin{array}{c}\text { Escherichid } \\
\text { coli }\end{array}$ \\
\hline SH1031 & + & + & + & H & 4 & + \\
\hline SH1036 & + & 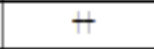 & + & + & 4 & + \\
\hline SH1087 & 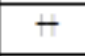 & H & + & + & 4 & + \\
\hline \begin{tabular}{|l|} 
SH1091 \\
\end{tabular} & + & H & + & + & 4 & + \\
\hline SH1108 & + & + & + & + & + & + \\
\hline SH1109 & 4 & 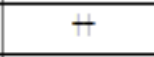 & + & + & 4 & + \\
\hline SH1111 & - & H & + & + & - & H \\
\hline SH1146 & + & 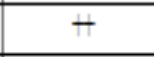 & + & + & 4 & 4 \\
\hline SH1183 & + & + & + & + & 4 & + \\
\hline SH1232 & + & 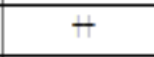 & + & + & 4 & + \\
\hline SH1233 & + & $H$ & + & + & 4 & + \\
\hline IGG & + & t & + & H. & 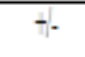 & + \\
\hline
\end{tabular}

\section{Resistance to simulated GIT conditions}

We measured the survival of all Lactobacilli isolates in simulated gastric fluid (SGF) and simulated intestinal fluid (SIF) as previously reported (8). Almost identical numbers of cells were recovered on MRS plates from treated and untreated cells of all 11 isolates, indicating an almost total resistance to both treatments. We then analysed whether cells exposed to simulated gastric fluid were still able to grow in simulated intestinal conditions. To this aim exponentially growing cells of all 11 isolates were exposed to SGF for 1 hour, then diluted to $0.05 \mathrm{OD}_{600 \mathrm{~nm}}$, and incubated anaerobically in MRS (pH8.0) supplemented with pancreatin (1 g/l, pH 8.0) and the optical density measured every hour for 18 hours. All strains were able to grow and very similar data were collected for all strains. Figure (1) reports the growth curves of treated and untreated cells for four representative strains. In all cases a long lag phase was observed, but once that growth was started the growth rates appeared similar to that of untreated cells. We cannot exclude the possibility that pancreatin inhibited growth and that after 8-14 hours the enzyme was no longer active, thus allowing the cells to enter the exponential growth phase. However, in such case we would expect cell growth to start at similar time points in all samples. As can be observed in Figure (1), for the various isolates cell growth started at different time points (i.e. about after 8 hours for B. breve, about 11 hours for L. mucosae SH1233 and about 13 hours for L. mucosae SH1091 and L. gasseri). Since we did not observe any mortality on plates due to the treatment in SGF conditions, we believe it is unlikely that the long delay is due to reduced number of live cells after the SGF treatment. For these reasons we favor the idea that the long lag phase experienced by cells subjected to SGF and then grown in SIF was due to the need of treated cells to adapt their metabolism to the new growth conditions. 

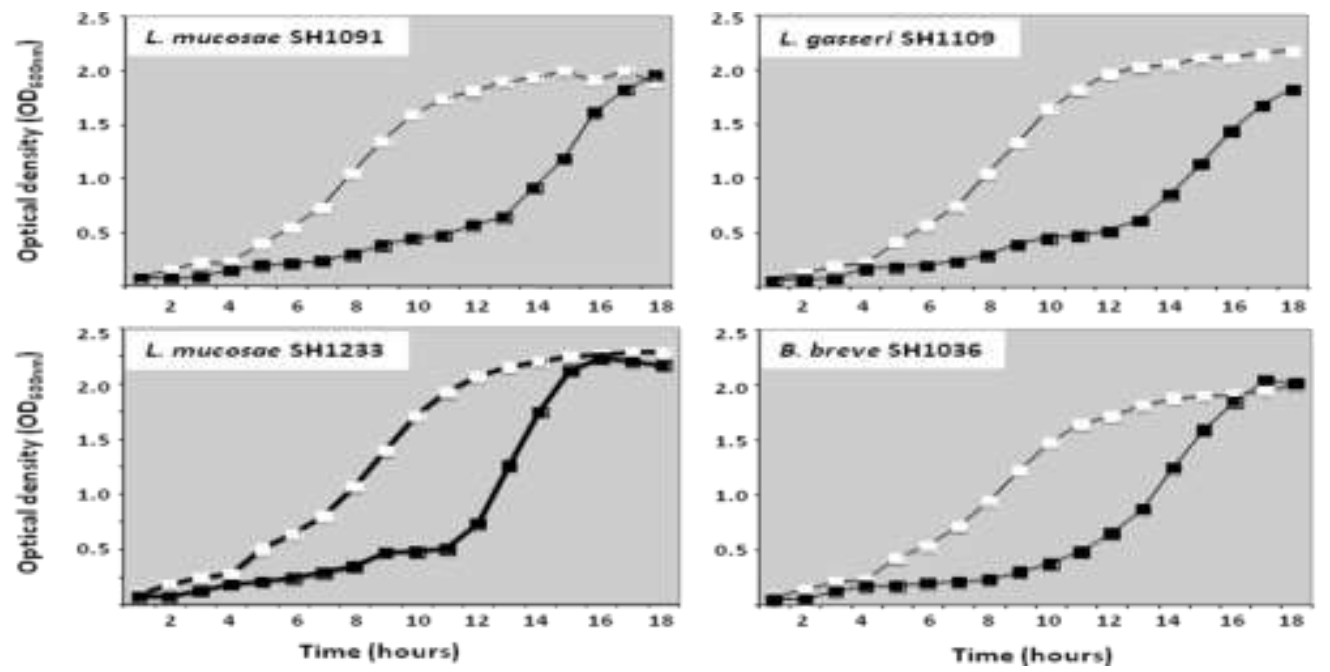

Figure 1: Growth curves of treated (closed symbols) and untreated (open symbols) cells. Overnight cultures of the various strains were either treated with pepsin at $\mathrm{pH} 2$ for 1 hour at $37^{\circ} \mathrm{C}$ or left in MRS broth at $37^{\circ} \mathrm{C}$, then diluted to $0.05 \mathrm{OD}_{600 \mathrm{~nm}}$, and used to inoculate MRS (open symbols) or MRS pH 8supplemented with pancreatin (closed symbols) and OD measured every hour for 18 hours.

\section{Biofilm formation}

All 11 isolates of Lactobacilli were tested for their ability to form biofilm in microtiter plate assays (14). $L$. rhamnosus GG (LGG), one of the clinically beststudied probiotic organisms (3) and a known biofilm producer (14), was used as a reference strain. Since biofilm formation is known to depend on environmental conditions (14), we measured the production of biofilm after exposure of our isolates to simulated gastric fluid and in simulated intestinal conditions, as described above. As reported in Figure (2), all isolates produced a biofilm and the SGF-SIF treatments did not affect significantly the amount of biofilm produced. Production of biofilm, when bacteria was transited the stomach tract and colonize the intestine was an important feature for a potential probiotic strain, since biofilms have protective and adhesive properties and have been associated to a longer persistence of bacteria in the GIT of animals $(8,14)$.

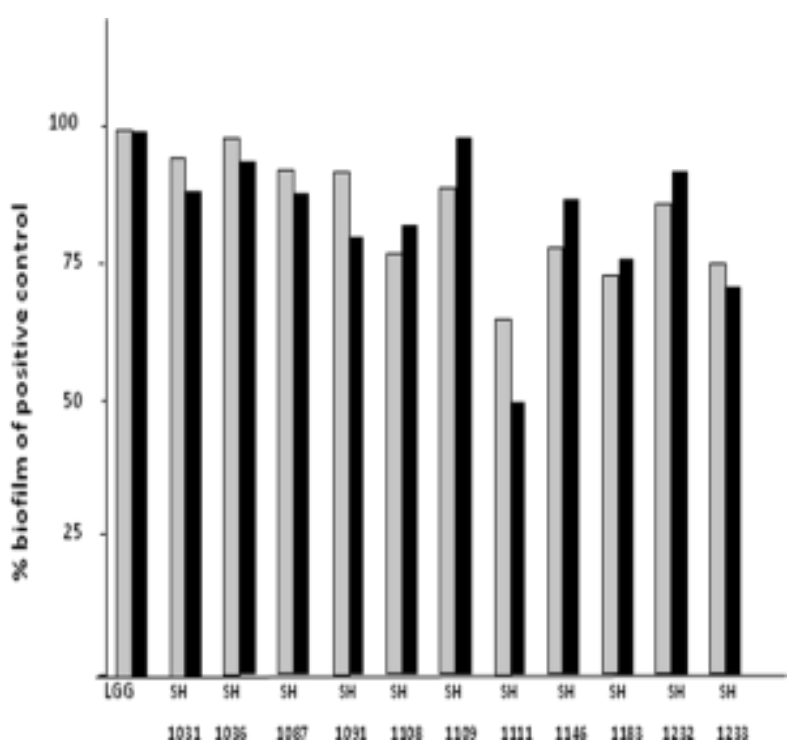

Figure 2: Biofilm formation. The abilities of biofilm formation by the various isolates are expressed in comparison with that of strain LGG. Values obtained for strain LGG were taken as $100 \%$. Biofilm formation was monitored in MRS broth (grey bars) and in MRS pH 8-supplemented with pancreatin (black bars). The data shown are representative of at least three independent experiments, each with three biological replicates. 


\section{Discussion}

Ileal biopsies from healthy human volunteers were used to isolate anaerobic bacteria specifically and tightly bound to the ileum. Following a previously reported procedure (17) we separated the epithelial cells from the mucus layer. Most bacteria were associated to the mucus and only a minority remained attached to the epithelial cells. We characterized the anaerobic bacteria attached to the epithelial cells and, in particular, focused our attention on the rod-shaped ones. Only one colony of those apparently identical from each ileal sample was selected for further characterisation. As a result, eleven rod-shaped isolates were identified to the species level as Bifidobacterium breve (1 isolate), Lactobacillus gasseri (2 isolates) and Lactobacillus mucosae (8 isolates). Since most isolates either come from different ileal samples or belong to different bacterial species (Table 1) only strains SH1087, SH1091 and SH1108 could be potential siblings. However, further characterization of those three strains indicated that SH1108 behaves differently with respect to the other two for mucin-degradation activity (Table 3) and therefore, only SH1087 and SH 1091 could be potential siblings. L. mисоsae and L. gasseri are normal inhabitants of the gastrointestinal tract of humans (10) and various other mammals $(6,12,16) . L$. gasseri is a well characterised species, known to represent the major homo fermentative Lactobacillus species of the human intestine $(14,19)$. L. mucosae is, instead of a poorly characterized species, firstly isolated in a study aimed at the isolation of L. reuteri (18). The similarities between $L$. reuteri and $L$. mucosae also depend on the presence in both species of the mub gene, encoding a cell-surface protein with mucin-binding activity. It is interesting that the $\mathrm{G}+\mathrm{C}$ content of mub of $L$. gasseri is similar to the overall $\mathrm{G}+\mathrm{C}$ content of $L$. mucosae and different from that of other L. reuteri genes. Based on this and on the observation that the mub gene has been found in all L. mucosae but only in some $L$. reuteri strains, Ross et al., 2000 suggest that L. mucosae may be the source of mub and $L$. reuteri is a recipient of the gene at some point during the course of evolution. In all studies in which L. mucosae and L. gasseri have been found associated to intestinal samples, they had never been indicated as predominant in number with respect to other Lactobacillus species. In a study by Kinoshita et al., (12), for example, $L$. gasseri and $L$. mucosae were identified as 10 and $3 \%$ of the total LAB population, respectively, in human colonic mucin. Although the low number of isolates of our study does not allow us to draw statistically relevant conclusions, we propose that the extensive washing and DTT treatment we performed on the ileal samples removed most of the loosely attached bacteria, allowing us to isolate a subpopulation of bacteria tightly associated to the epithelial cells. L. mucosae and $L$. gasseri would then be predominant species among those bacteria tightly attached to the epithelial cells of the ileal tract of the human intestine. Our hypothesis is supported by the extremely similar physiological properties that characterize this sub-population of intestinal bacteria: i) all produce antimicrobial molecules similarly active against all tested pathogens. This is a peculiar feature since LAB from different sources have a more heterogeneous profile of antimicrobial activity (see strain LGG); ii) all are resistant to simulated gastric fluid and able to grow efficiently in simulated intestinal fluid after exposure to gastric conditions; iii) all produce biofilm also in conditions that mimick gastric and intestinal environments. The tight association with the epithelial cells, presumably indicative of a direct interaction with the host cell, together with the physiological properties discussed above makes the sub-population of intestinal bacteria that we isolated very promising as probiotic strains for human use. A future challange will be to verify their presence and biologic behaviour in human inflammatory conditions such as Inflammatory Bowel Diseases.

\section{$\underline{\text { References }}$}

H.M.M. Arafa Possible contribution of B-glycosidases and caspases in the cytotoxicity of novel glycoconjugates in colon cancer cells. Invest. New Drugs (published on line on May 5th 2009).

L. Baccigalupi, A. Di Donato, M. Parlato, D. Luongo, V. Carbone, M. Rossi, E. Ricca, M. De Felice, Two small, surface-associated factors mediate adhesion of a food-isolated strain of Lactobacillus fermentum to Caco-2 cells. Res. Microbiol. 156 (2005) 830-836.

M. Banasaz, E. Norin, R. Holma, T. Midtvedt, Increased enterocyte production in gnotobiotic rats mono-associated with Lactobacillus rhamnosus GG. Appl. Environ. Microbiol. 68 (2002) 3031-3034.

Y. Benno, K. Sawada, T. Mitsuoka, The intestinal microflora of infants: composition of fecal flora in brest-fed and bottle-fed infants. Microbiol. Immunol. 28 (1984) 975-986.

S.-S. Bun, M. Laget, A. Chea, H. Bun, E. Ollivier, R. 
Elias, Cytotoxic activity of alkaloids isolated from Stephania rotunda in vitro cytotoxic activity of cephranthine. Phytotherapy Res. 23 (2009) 587-590.

M. Busconi, S. Reggi, C. Fogher, Evaluation of biodiversity of lactic acid bacteria microbiota in the calf intestinal tracts. Antoine van Leeuwenhoek 94 (2008) 145-155.

P.B. Eckburg, E.M. Bik, C.N. Bernstein, E. Purdom, L. Dethlefsen, M. Sargent, S.R. Gill, K.E. Nelson, D.A. Relman, Diversity of the human intestinal microbial flora. Science 308 (2005) 1635-1638.

S. Fakhry, I. Sorrentini, E. Ricca, M. De Felice, L. Baccigalupi, Characterization of spore forming Bacilli isolated from the human gastrointestinal tract. J Appl. Microbiol. 105 (2008) 2178-2186.

D. Ivanov, C. Emonet, F. Foata, M. Affolter, M. Delley, M. Fisseha, S. Blum-Sperisen, S. Kochhar, F. Arigoni, A serpin from the gut bacterium Bifidobacterium longum inhibits eukaryotic elastase-like serine proteases. J. Biol. Chem. 281 (2006) 17246-17252.

H. Honda, F. Kataoka, S. Nagaoka, Y. Kawai, H. Kitazawa, H. Itoh, K. Kimura, N. Taketomo, Y. Yamazaki, Y. Tateno, T. Saito, $\square$-galactosidase, phospho-b-galactosidase and phospho-bglucosidase activities in lactobacilli strains isolated from human faeces. Lett. Appl. Microbiol. 45 (2007) 461-466.

M.J. Hopkins, R. Sharp, G.T. Macfarlane, Age and disease related changes in intestinal bacteria populations assessed by cell culture, 16S rRNA abundance and community fatty acid profile. Gut 48 (2001) 198-205.

J.M. Korhonrn, Y. Sclivagnotis, A. von Wright, Characterization of dominant cultivable lactobacilli and their antibiotic resistance profile from faecal samples of weaning piglets. J. Appl. Microbiol. 103 (2008) 2496-2503.

M.J. Kullen, T.R. Klaenhammer, Genetic modification of intestinal Lactobacilli and Bifidobacteria. Curr Issues Mol Biol. 2 (2000) 41-50.

S. Lebeer, T.L.A. Verhoeven, M. Perea Velez, J. Vanderleyden, S.C.J. De Keersmaecker, Impact of Environmental and genetic factors on biofilm formation by the probiotic strain Lactobacillus rhamnosus GG. Appl. Environ. Microbiol. 73 (2007) 6768-6775.

M.A. Mahowald, F.E. Rey, H. Seedorf, P.J. Turnbaugh, R.S. Fulton, A. Wollam, C. Wang, V. Magrini, R.K. Wilson, B.L. Cantarel, P.M. Coutinho, B.
Henrissat, L.W. Crock, A. Russell, C. Verberkmoes, R.L. Hettich, J.I. Gordon, Characterizing a model human gut microbiota composed of members of ita two dominant bacterial phyla. Proc. Natl. Acad. Sci. USA 106 (2009) 5859-5864.

T.J.K. Manninen, M.L. Rinkinen, S.S. Beasley, P.E. Saris, Alteration of the canine small-intestine lactic acid bacterium microbiota by feeding of potential probiotics. Appl. Environ. Microbiol. 72 (2006) 6539-6543.

H.M. Martin, B.J. Campbell, C.A. Hart, C. Mpofu, M. Nayar, R. Singh, H. Englyst, H.F. Williams, J.M. Rhodes, Enhanced Escherichia coli adherence and invasion in Crohn's disease and colon cancer. Gastroenterology 127 (2004) 80-93.

T. Mitsuoka, Intestinal flora and aging. Nutr Rev. 50 (1992) 438-446.

S. Ross, F. Karner, L. Axelsson, H. Jonsson, Lactobacillus mucosae sp. nov., a new species with in vitro mucus-binding activity isolated from pig intestine. Int. J. System Evol. Microbiol. 50 (2000) 251-258.

E.J. Schiffrin, S. Blum, Interactions between the microbiota and the intestinal mucosa. European J. Clin. Nutrution 56 (2002) 560-564.

P.J. Turnbaugh, M. Harnady, T. Yatsunenko, B.L. Cantarel, A. Duncan, R.E. Ley, M.L. Sogin, W.J. Jones, B.A. Roe, J.P. Affourtit, M. Egholm, B. Henrissat, A.C. Heath, R. Knight, J.I. Gordon, A core gut microbiome in obese and lean twins. Nature 457 (2009) 480-485.

E.J. Woodmansey, Intestinal bacteria and ageing. J. Appl. Microbiol. 102 (2007) 1178-1186.

H. Zhang, J.K. DiBiase, A. Zuccolo, D. Kudrna, M. Braidotti, Y. Yu, P. Parameswaran, M.D. Crowell, R. Wing, B.E. Rittmann, R. KrajmalnikBrown, Human gut microbiota in obesity and after gastric bypass. Proc. Natl. Acad. Sci. USA 106 (2009) 2365-2370. 